\title{
Functional Design of a Research Information Management Platform
}

\author{
Min-Hui Wang \\ Information Technology College, Shanghai Jianqiao University, Shanghai, China \\ E-mail: wmh_gench@126.com
}

\begin{abstract}
Nowadays Software College is still a lack of unified management platform for research information, so that teachers have difficulty in obtaining scientific research data. To improve the level of scientific research in Software College, it is necessary toprovide a superior research information management platform for all the teachers. This paper aims to put forward a practical and feasible project to improve the management of scientific research information and the document describes the user needs in details.
\end{abstract}

Keywords-scientific research data; management platform; project management

\section{INTRODUCTION}

At present, Software College is still a lack of unified management platform for research information [1], which makes it difficult obtain all kinds of scientific research data. Then cause some of the following situations: (1) Scientific research information is closed: Only the project managers or the person in charge of project usually know the project or the result information, research achievement statistics need to be notified by sending mail. Through information collection in an original and manual method, the leaderships of college or department and the relevant person in charge cannot understand of the current scientific research and situation in time. (2)Valuable information cannot be saved: If there is no a suitable platform can save years of scientific research project application data, application need to be started from scratch and reinvent the wheel in the year after year, resulting in the waste of manpower and resources and other teachers cannot learn from it. (3)Academic resources cannot be shared: College leaderships and teachers do not have the appropriate path to view or access the Institute's research results. If you need to search through Baidu or Google and other search engines to look at a teacher's paper, it is not necessarily able to download for free even if you spend much time.

To improve the level of scientific research in Software College, it is necessary to provide a superior research information management platform for all the teachers. At present, the school's public database system also contains the scientific research management module, but the system aims at the management of the projects and the results of the project (papers, books, patents) which have been established by the logged-in teachers, it focuses on financial management, such as the allocation and inquiries of funds. Compared with the requirements of scientific research management in Software College, there are obvious deficiencies in the system functions. Therefore, it is very necessary to develop a new scientific research management information system of Software College to meet the requirements of improving the level of scientific research management; it is also the original intention of this project. This document is a project requirements specification which describes the user needs in details.

\section{PROJECT OBJECTIVES}

After the completion, the project will achieve the following goals:

- Finish the collection, preservation, audit, inquiry and sharing of project application data (emphasis on information management before starting the project).

- Project management has been established: Such as information entry, project management (emphasis on project process management), results management (emphasis on intelligent retrieval [2], convenient, fast inquiry to the desired outcome information)and so on. The system will store all the teacher's project information, papers or patents and other results of information, project results can be specific to the development of the project documentation, the paper can be specific to the electronic version of the full text of the paper.

- Provide college or department statistics as a unit and inquiry functions, the leaderships of college or department can easily get the latest scientific research information and statistical information through the system.

\section{FUNCTIONAL REQUIREMENTS}

\section{A. Project Application Module}

1) Summary: Due to the different types of projects required to application process is very different, so the current system of project application module is only for the internal projects in Software College, providing the application data collection, preservation, audit, inquiry and sharing (vertical sharing[3]). The business process of internal projects in Software College is shown in Figure 1. 


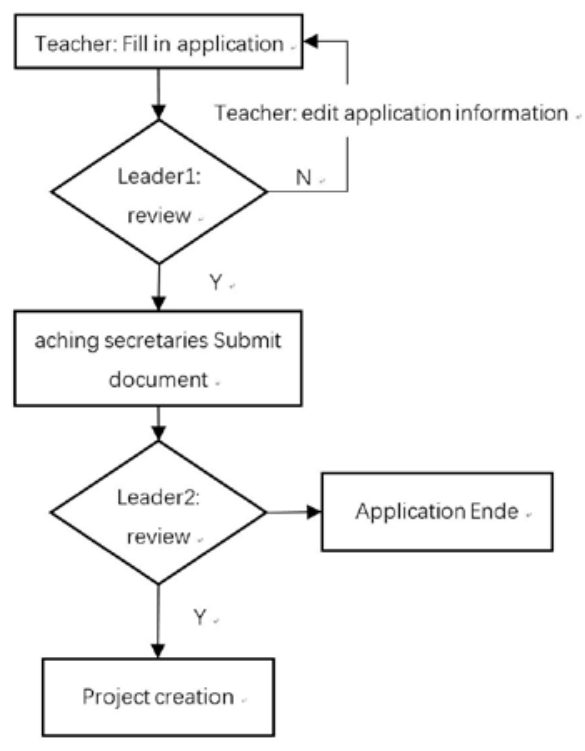

Figure 1 The business process of project application.

2) Collection and preservation of project application data: System allows users to upload a variety of formats of the project application information(such as word and pdf),it will be saved to the server corresponding to the user's storage space.

3) Inquiry of project application data: Users can inquire and download their own preservation of project application data over the years.

4) Audit of project application data: System can set up the project application data of the audit unit (college, department or institute) or the audit person, the users who have the audit authority will be able to audit the application data.

5) Sharing of project application data: If the project application information can be made public (open to all) or partially open (open to some designated teachers), a teacher who has the authority will be able to download the information. Leadership can do inquiries and statistics to the jurisdiction of all projects within the scope, those who have approval authority can download and approve.

\section{B. Project Management Module}

1) Summary: Scientific research Secretary import into the specified format of the Excel file, add established project information, and according to the update situation of the public database [4], regularly updates data. Corresponding to the management of the project has been established. Such as project management, fund management, contract management, achievement management, etc. This part of the function needs support provided by the school public database.

2) (Established) Project management: Project management is divided into three modules: my project project establishment and additional contract amount. My project can check the established project has been hosted or participate by the teacher. A new project can be added to a project. Increase in the amount of the contract can increase the amount of the project that has been approved. These functions of the school public database have already had and can make full use of existing functions.

In addition, two parts of the function need to increase:

(1)Leadership can inquire and statistics functions for all teachers' projects under the jurisdiction of the project. Leadership can inquire and statistics a single teacher, some teachers, colleges, departments and institutes.

(2)Each teacher can upload their own projects and the results of the information, such as the electronic version of the full text of the paper. This function may lead that the data of the software college's scientific research management system and the data in the public database is not synchronized [5].

(3)Achievement management: Functions include patent management, paper management, book management, etc... Be able to input, edit, delete and inquire logged-in teacher's results. This part also can directly use the function the school public database has already had.

\section{User Management Module}

1) Summary: Role management, user function management and user account management, based on the role of the authority function, but also for individual accounts to give specific permissions function. (This part of the function is only for the system administrator).

2) Add, edit, and delete roles: System default roles are: system administrators, students, teachers, school leaderships, leaderships of department and institute, scientific research secretary, other roles can be added through the system. The system administrator can add the user account and assign the role directly on the page. They can also import Excel files (specified format), batch adding user accounts. When enter the system, students login system with student ID, the default role is the student; teachers login system with employee number, the default identity is the teacher; a teacher can also have multiple identities, such as one is a teacher, the other is a leadership, then login with advanced identity as the default identity. In the system, two identities actually exist, and it can also do operate that both the identities have the permission to. (For example, you can inquire your own project [teacher status]; you can examine the teacher's application [leadership status]).

3) Permissions to add, edit, and delete (for selected characters): This feature is only open to a specific account, such as the system administrator. According to the different roles, each role corresponds to a set of permissions function (reflect in the different system menu items, buttons). It can be independent in the role and specify a specific permission function for the account. 


\section{Statistics and Inquiry Module}

1) Summary: Statistics and inquiry module can classify the information of the project, the paper and the results of the system. Statistical results are displayed on the web page by category. In addition to inquire results output on the page, provide Excel export functions at the same time.

2) Scientific research statistics: Statistical module can classify and count the scientific research information, intellectual property and project information in the system. Each teacher can see the statistical results related to the individual, as shown in Figure 2; scientific research secretary and leadership can see the jurisdiction of the department of classification statistics results, as shown in Figure 3.

3) Scientific inquiry: Inquiry module can inquire projects, papers, results and other contents in the system, the results of the inquiry output on the page. You can also export the Excel file (as a Excel chart data source, or specify a specific format).

Location: research achievement statistics

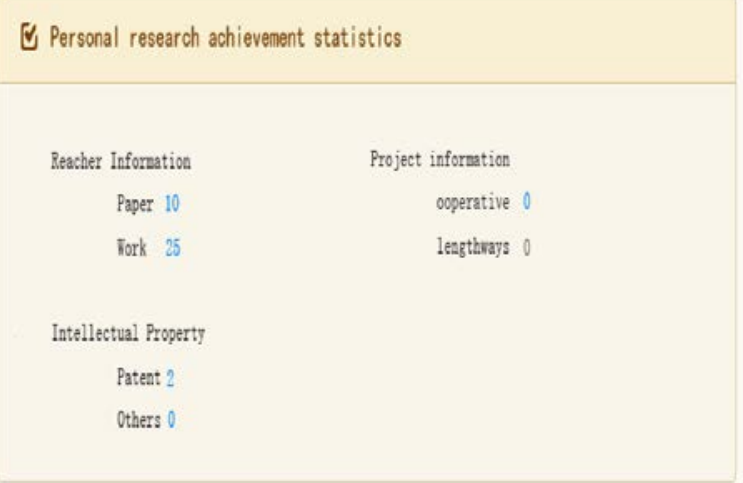

Figure 2. Statistics diagram of personal research achievements.

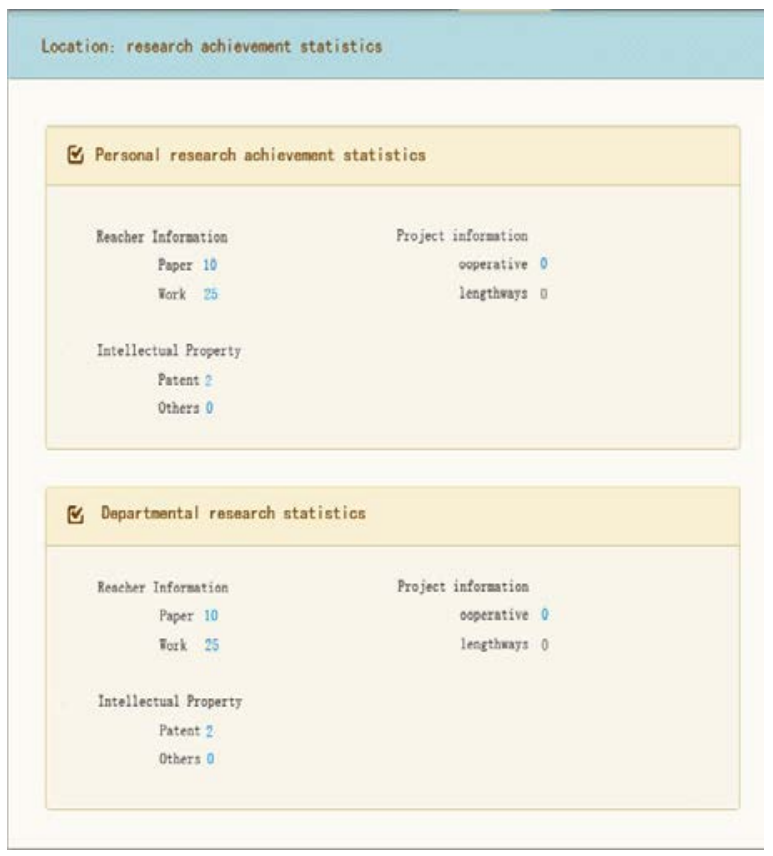

Figure 3. Statistics diagram of scientific research secretary/leaderships' research achievements.

According to the role of the permissions, you can retrieve [6] the contents of different ranges. For example: the scientific research secretary and the college leaders can retrieve all the results, as shown in Figure 4. The teacher can only retrieve the research information related to him, as shown in Figure 5.

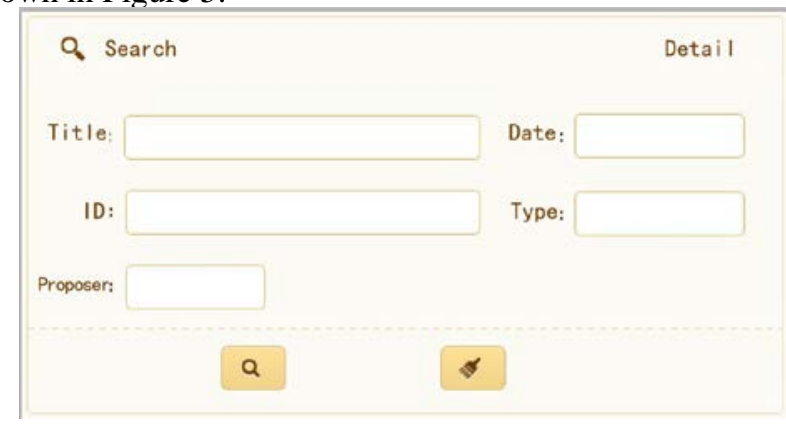

Figure 4. Inquiry interface diagram of scientific research secretary/leaderships' research achievements.

\begin{tabular}{ll}
\hline Statistics & Information \\
\hline Departmental statistics List & $\begin{array}{r}\text { Inquiry interface diagram of personal } \\
\text { research achievements }\end{array}$ \\
\hline
\end{tabular}

According to the classification of scientific research achievements in the school public database: the research reports, the new drug certificate [7], technical achievements, 
patents, audio and video software, other results displayed in pagination, as shown in Figure5.

\section{KEY TECHNOLOGY}

\section{A. Asynchronous Data Access}

In order to speed up the system page update speed, users have a real-time response to the experience, through the system client to increase the Ajax engine, client and user data to achieve asynchronous access. When the user opens a Web page, load the Ajax engine. Ajax engine initialization, began to initialize the XMLHttpRequest object, to capture user behavior, beginning with the user's interaction. When a user sends out some requests, Ajax sends the user's data asynchronous request to the controller ActionServlet in the background.

\section{B. System Security}

Research management system security is mainly data security issues, including user login information, academic achievements and scientific research project information security, etc.. In order to avoid unauthorized tampering with the data, the system should first determine whether the user has the right to send the request when the data is modified or deleted. Because the user rights data is stored in the database, and the user update data pages are usually continuous, if each receive a data update request to query a database, the efficiency of the system will be very low. Therefore, in order to improve the system efficiency, the system uses the Session JSP object. When a user visits for the first time a page on the server, JSP engine will generate a session object, the session object invokes the corresponding method and stores the customer visit each page submitted during all kinds of information, such as name, password, and so on. The Session object will be assigned a DI number (String type), according to the JPS number ID engine with the user to establish a one-to-one correspondence between. In this way, the system in determining a user permissions, just access to a database, some useful information is stored in the session, after the system is in the execution of the user request, direct access to the information stored in the session, thereby avoiding the repeated visits to the background data, the system operation efficiency is improved.

\section{CONCLUSION}

According to the inside the university scientific research project and academic achievements management content, work flow, using based on J2EE MVC pattern using struts, spring and hibernate integration architecture design and implementation of a scientific research management information system of university based on Web. System features simple, practical, taking into account the future change and management mode of the concept of scientific management of change, the system has reserved a certain number of interface for the system function expansion, to ensure the scalability of the system. The implementation of scientific research management information system has greatly improved the efficiency of scientific research teachers and management departments, and realized the process of scientific research work in schools, standardized management.

\section{REFERENCES}

[1] V. V. Brezhneva and R. S. Gilyarevskii, On the content of the research and scientific field of information management, Scientific and Technical Information Processing, 2013, Vol.40 (4), pp.185-189

[2] Qiao Lin, Huang Wei-tong, Wen Qi and Fu Xiao-long, An integrated information retrieval support system for campus network, Wuhan University Journal of Natural Sciences, 2006, Vol.11 (1), pp.42-46

[3] Toshiyuki Miyamoto, Yasuhiro Morita and Sadatoshi Kumagai, Vertical partitioning method for secret sharing distributed database system, IEICE Transactions, 2006, Vol.89-A

[4] McDaniel Anna M and Poynton Mollie R, "Mining" data in public databases, Clinical Nurse Specialist, 2004, Vol.18 (3), pp.113-5

[5] Julien Denoulet and Alain Mérigot, An architecture based on reconfigurability and asynchronism for real-time image processing, J. Real-Time Image Processing, 2008, Vol.3

[6] Data Retrieval; Reports from T. Bluhm and co-researchers add new data to research in data retrieval, Information Technology Newsweekly, 2010

[7] Manasse H R, Stewart J E and Johnson K, Certificate of need and statement of social impact as requirements for new drug approvals, Journal of the American Pharmaceutical Association, 1977, Vol.17 (9), pp.567-71 